\title{
Regulation Mechanism of Long Noncoding RNAs in Colon Cancer Development and Progression
}

\author{
Xiaohuan Tang, Xiaofang Qiao, Chao Chen, Yuanda Liu, Jiaming Zhu, and Jingjing Liu \\ Department of Gastrointestinal Nutrition and Hernia Surgery, The Second Hospital of Jilin University, Changchun, China.
}

\begin{abstract}
Colorectal cancer (CRC) is the second most common cause of cancer-related death worldwide, and its high rates of relapse and metastasis are associated with a poor prognosis. Despite extensive research, the underlying regulatory mechanisms of CRC remain unclear. Long noncoding RNAs (IncRNAs) are a major type of noncoding RNAs that have received increasing attention in the past few years, and studies have shown that they play a role in many biological processes in CRC. Here, we summarize recent studies on IncRNAs associated with CRC and the signaling pathways and mechanisms underlying this association. We show that dysregulated lncRNAs may be new prognostic and diagnostic biomarkers or therapeutic targets for clinical application. This review contributes not only to our understanding of CRC, but also suggests novel signaling pathways associated with lncRNAs that can be targeted to block or eradicate CRC.
\end{abstract}

Key Words: Colorectal cancer, IncRNA, signaling pathway

\section{INTRODUCTION}

Colorectal cancer (CRC) is one of the most common malignancies worldwide, and ranks the second most common cause of cancer-related death for both sexes. ${ }^{1}$ The morbidity and mortality of CRC have increased in the past few years, especially in developing counties in Asia, such as China. ${ }^{2}$ Despite advances in the prevention, diagnosis, and treatment of CRC, effective treatment strategies for this disease have yet to be developed. ${ }^{3}$ Metastasis and relapse are the main causes of failure in the treatment of CRC. ${ }^{4}$ Therefore, elucidating the molecular mechanisms underlying CRC progression and me-

\footnotetext{
Received: November 19, 2018 Revised: January 23, 2019

Accepted: January 24, 2019

Co-corresponding authors: Jiaming Zhu, PhD, Department of Gastrointestinal Nutrition and Hernia Surgery, The Second Hospital of Jilin University, No. 218 Ziqiang Street, 130041 Changchun, China.

Tel: 86-431-81136210, Fax: 86-431-81136210, E-mail: Zhujiaming75@sina.com and Jingjing Liu, PhD, Department of Gastrointestinal Nutrition and Hernia Surgery, The Second Hospital of Jilin University, No. 218 Ziqiang Street, 130041 Changchun, China.

Tel: 86-431-81136210, Fax: 86-431-81136210, E-mail: jingjingstarone@163.com

-The authors have no potential conflicts of interest to disclose.
}

(C) Copyright: Yonsei University College of Medicine 2019

This is an Open Access article distributed under the terms of the Creative Commons Attribution Non-Commercial License (https://creativecommons.org/licenses/ by-nc/4.0) which permits unrestricted non-commercial use, distribution, and reproduction in any medium, provided the original work is properly cited. tastasis is important. Recent evidence supports the involvement of various signaling pathways in the pathogenesis and development of CRC. ${ }^{5}$ Activation of the Wnt/ $\beta$-catenin cascade is a common phenomenon in $\mathrm{CRC},{ }^{6}$ and its downstream target genes can promote tumorigenesis by inducing cell cycle progression and abnormal proliferation. ${ }^{7,8}$ The Wnt/ $\beta$-catenin signaling pathway is involved in the regulation of epithelialmesenchymal transition (EMT) and cell proliferation, invasion, and migration in CRC. This pathway also plays a vital role in regulating epithelial stem cell self-renewal, and the self-renewal ability of CRC stem cells is important for the initiation of CRC. ${ }^{9}$ Alterations in the Wnt/ $\beta$-catenin signaling pathway affect CRC, providing a potential target for treatment. The Janus kinase/signal transducers and activators of transcription (JAK/STAT) signaling pathway, the PI3K/AKT signaling pathway, the MAPK cascade, the p53 pathway, Notch signaling, nuclear factor $\kappa \mathrm{B}(\mathrm{NF}-\kappa \mathrm{B})$ signaling, and other pathways have also been shown to affect the development of CRC.

Increasing evidence indicates that noncoding RNAs (ncRNAs) play important regulatory roles in various biological processes, including cancer development. ${ }^{10}$ Long noncoding RNAs (lncRNAs) are ncRNAs longer than 200 nucleotides in length that are not translated into proteins. ${ }^{11,12}$ Recent studies have reported that various lncRNAs act as modulators of carcinogenesis and progression in human CRC. ${ }^{13}$ LncRNAs are required for CRC cell proliferation and migration, ${ }^{14}$ are associ- 
ated with a poor prognosis in CRC, ${ }^{15}$ and promote colon tumorigenesis. ${ }^{16}$ LncRNAs exert these effects by regulating various signaling pathways. ${ }^{17}$ For example, the lncRNA CCAL promotes CRC progression by regulating the $\mathrm{Wnt} / \beta$-catenin signaling pathway. ${ }^{18}$ These studies provide new insights with which to improve our understanding of the mechanisms underlying CRC development. Herein, we summarize the latest findings on lncRNAs associated with CRC and highlight associated regulatory mechanisms and signaling pathways that may lead to the development of IncRNA-based approaches in the treatment of CRC.

\section{UNDERLYING MECHANISMS OF LNCRNAS IN THE REGULATION OF CRC}

LncRNAs exert effects on gene expression at the transcriptional and post-transcriptional levels via various mechanisms. LncRNAs can bind to DNA, RNA, and proteins to influence transcriptional initiation, RNA stability, or the activity of signaling pathways. LncRNAs serve as a scaffold for the recruitment of transcriptional factors to the promoter region to affect gene expression. Several lncRNAs are involved and play critical roles in the development of cancers, such as malignant proliferation, metastasis, invasion, anti-apoptosis effects, and therapeutic resistance (Table 1). Recent studies have focused on the regulation of lncRNAs in CRC cells through signaling pathways. The underlying mechanisms are addressed in the following paragraphs.

\section{LncRNAs regulate CRC cells through the Wnt/ $\beta$-catenin cascade}

$\beta$-catenin affects both carcinogenesis and development. Overexpression of Wnt/ $\beta$-catenin pathway members is a common feature in CRC. ${ }^{6,19}$ Studies suggest that $\beta$-catenin plays a role as a transcription factor in concert with TCF1 and LEF1 to activate downstream target genes. ${ }^{20}$ When Wnt ligands bind to the receptor FZD or LRPs, $\beta$-catenin is released from the $\beta$-catenin destructive complex, which consist of Axin, APC, and GSK3 $\beta$. The activation of the Wnt cascade may be induced by mutations of APC. ${ }^{21}$ Then, $\beta$-catenin accumulates and is translocated into the nucleus to activate the downstream genes of the Wnt/B-catenin pathway through hcCF/ LEF, and it may continue to induce the process of EMT through increasing the expression of key proteins. ${ }^{22,23}$ Over the past few years, an increasing number of studies have shown that EMT plays a vital role in cancer cell metastasis and invasion. ${ }^{24}$ Some IncRNAs have proven to affect EMT by or not by Wnt/ $\beta$-catenin pathway ${ }^{23-29}$ Several IncRNAs affect the Wnt/ $\beta$-catenin cascade to regulate CRC (Table 2), and the regulatory mechanisms are listed in Fig. 1.

Some lncRNAs, such as CCAL, CASC11, and CCAT2, can bind to proteins or microRNAs (miRNAs) to affect the Wnt/ $\beta$-catenin pathway indirectly. The lncRNA CCAL can bind to activator protein $2 \alpha$ (AP-2 $\alpha$ ), which can combine with $\beta$-catenin and APC to form a complex, thereby weakening $\beta$-catenin/ TCF-4 interactions in CRC. The IncRNA CASC11 may activate the Wnt/ $\beta$-catenin cascade by binding to hnRNP-K, which can form a complex with GSK3 $\beta$, TCF4, $\beta$-catenin, and AXIN to inhibit the degradation of $\beta$-catenin. The physical interaction between TCF7L2 and the IncRNA CCAT2 can increase

Table 1. Signaling Pathways of LncRNAs Participating in the Regulation of Colorectal Cancer

\begin{tabular}{|c|c|c|c|}
\hline LncRNA & Signaling pathway & Effect & Ref \\
\hline CCAL & Wnt/ $\beta$-catenin & Oncogene & 18 \\
\hline CASC11 & Wnt $/ \beta$-catenin & Oncogene & 30 \\
\hline CCAT2 & Wnt/ $\beta$-catenin & Oncogene & 31 \\
\hline MALAT1 & Wnt $/ \beta$-catenin & Oncogene & 32 \\
\hline SNHG1 & Wnt/ $\beta$-catenin & Oncogene & 33 \\
\hline CRNDE & Wnt $/ \beta$-catenin & Oncogene & 27 \\
\hline ZEB1-AS1 & Wnt/ $\beta$-catenin & Oncogene & 34 \\
\hline $\mathrm{H} 19$ & Wnt/ $\beta$-catenin & Oncogene & 35 \\
\hline lincRNA-p21 & Wnt/ $\beta$-catenin & Anti-oncogene & 36 \\
\hline XIST & Wnt/ $\beta$-catenin & Oncogene & 37 \\
\hline CTD903 & Wnt $/ \beta$-catenin & Anti-oncogene & 23 \\
\hline HNF1A-AS1 & Wnt $/ \beta$-catenin & Oncogene & 39 \\
\hline BCAT1 & Wnt $/ \beta$-catenin & Anti-oncogene & 40 \\
\hline AB073614 & JAK/STAT & Oncogene & 17 \\
\hline SBDSP1 & JAK/STAT & Anti-oncogene & 44 \\
\hline GACAT3 & JAK/STAT & Oncogene & 45 \\
\hline CASC2 & JAK/STAT & Oncogene & 46 \\
\hline AB073614 & PI3K/PTEN/AKT/mTOR & Oncogene & 51 \\
\hline DUXAP10 & PI3K/PTEN/AKT/mTOR & Oncogene & 52 \\
\hline RP11-708H21.4 & PI3K/PTEN/AKT/mTOR & Anti-oncogene & 53 \\
\hline IncRNA-422 & PI3K/PTEN/AKT/mTOR & Anti-oncogene & 54 \\
\hline PIncRNA-1 & PI3K/PTEN/AKT/mTOR & Oncogene & 50 \\
\hline CRNDE & MAPK & Oncogene & 58 \\
\hline NNT-AS1 & MAPK & Oncogene & 59 \\
\hline PURPL & p53 & Oncogene & 62 \\
\hline IncRNA-ROR & p53 & Oncogene & 63 \\
\hline SNHG1 & p53 & Oncogene & 64 \\
\hline ZFAS1 & p53 & Oncogene & 65 \\
\hline HNF1A-AS1 & p53 & Oncogene & 66 \\
\hline FAM83H-AS1 & Notch & Oncogene & 70 \\
\hline FOXD2-AS1 & Notch & Oncogene & 69 \\
\hline Inc-GNAT1-1 & $N F-\kappa B$ & Anti-oncogene & 74 \\
\hline GAS5 & $N F-\kappa B$ & Oncogene & 75 \\
\hline HOTAIR & $N F-\kappa B$ & Oncogene & 76 \\
\hline loc554202 & Caspase cleavage & Anti-oncogene & 77 \\
\hline MALAT1 & Chemokine & Oncogene & 79 \\
\hline DILC & IL & Anti-oncogene & 82 \\
\hline GAS5 & IL & Oncogene & 75 \\
\hline
\end{tabular}

IncRNA, long noncoding RNA; JAK, Janus kinase; STAT, signal transducers and activators of transcription; IL, interleukin; NF- $\mathrm{KB}$, nuclear factor $\kappa \mathrm{B}$. 
Table 2. The Regulation of LncRNAs in Wnt/B-Catenin Cascade

\begin{tabular}{lclc}
\multicolumn{1}{c}{ LncRNA } & Regulate & \multicolumn{1}{c}{ Target } & Ref \\
\hline CCAL & Up & AP-2 $\alpha$ & 18 \\
CASC11 & Up & hn-RNP-K & 30 \\
CCAT2 & Up & $\beta$-catenin/TCF & 31 \\
MALAT1 & Up & $\beta$-catenin/C-Myc/MMP-7 & 32 \\
SNHG1 & Up & $\beta$-catenin/TCF-4/MMP-9 & 33 \\
CRNDE & Up & cyclin-D1 & 37 miR-181a-5p \\
ZEB1-AS1 & Up & miR-181a-5p & 27 \\
H19 & Up & miR-200a & 34 \\
lincRNA-p21 & Down & MRE/miR-451 & 35 \\
XIST & Up & miR-34a & 36 \\
CTD903 & Down & $\beta$-catenin/EMT & 37 \\
HNF1A-AS1 & Up & $\beta$-catenin & 23 \\
BCAT1 & Down & $\beta$-catenin/c-Myc/MMP-2 & 40 \\
& & cyclin-D1 &
\end{tabular}

IncRNA, long noncoding RNA; AP-2 $\alpha$, activator protein $2 \alpha$; EMT, epithelialmesenchymal transition.

Wnt/ $\beta$-catenin signaling pathway activity. ${ }^{18,30,31}$ Some lncRNAs promote the nuclear localization of $\beta$-catenin to upregulate the Wnt/ $\beta$-catenin cascade, such as MALAT1 and SNHG1.32,33 MiRNAs are also important targets that help lncRNAs exert effects on signaling pathways by binding to a complex. For example, the lncRNAs CRNDE, ZEB1-AS1, H19, lincRNA-p21, and XIST affect the Wnt/ $\beta$-catenin signaling pathway by sponging or binding to miRNAs. ${ }^{34-38}$ In addition, lncRNAs can change the expression of certain vital proteins to affect the activation of the Wnt/ $\beta$-catenin cascade. The lncRNA CTD903 may downregulate Wnt/ $\beta$-catenin signaling and then decrease the expression of TCF, Snail, and Twist to suppress the EMT process, which is closely associated with the development of CRC. The lncRNA HNF1A-AS1 can induce CRC cell growth, invasion, and migration mediated by the Wnt/ $\beta$-catenin cascade by up-regulating the expression of $\beta$-catenin, cyclin D1, and c-Myc. LncRNA-BCAT1 overexpression inhibits $\beta$-catenin expression in CRC cells. ${ }^{23,39,40}$

\section{LncRNAs regulate CRC cells by affecting the JAK/STAT signaling pathway}

JAKs and STATs are essential molecules in cytokine signal transduction pathways. ${ }^{41}$ Despite their long-recognized pivotal roles in immunological responses, recent studies have shown that JAKs and STATs play important roles in cancer initiation and progression. ${ }^{42}$ The activated JAK/STAT pathway can inhibit cell apoptosis and promote the proliferation and invasion of tumor cells. ${ }^{43}$ Certain lncRNAs play a role in CRC by modulating the JAK/STAT pathway, acting as competing endogenous RNAs (ceRNAs) or by changing the expression of phosphorylated STAT3. The lncRNAs AB073614 and SBDSP1 contribute to the suppression of STAT3 phosphorylation, ${ }^{17,44}$ whereas the lncRNAs GACAT3 and CASC2 act as ceRNAs for specific miRNAs to indirectly up-regulate SP1 and STAT3 expression. ${ }^{45,46}$

\section{LncRNAs regulate CRC cells by affecting the PI3K/ PTEN/AKT/mTOR signaling pathway}

The PI3K/PTEN/AKT/mTOR signaling pathway regulates various biological processes in cells, such as gene expression, metabolism, cell growth, and metastasis. ${ }^{47}$ Although the effects of PTEN are frequently mediated by the negative regulation of the PI3K/PTEN/AKT/mTOR signaling pathway, it can also function as a suppressor independently. ${ }^{48}$ Recent studies have demonstrated that lncRNAs regulate cancer progression through the PI3K/PTEN/AKT/mTOR cascade, which plays important roles in CRC cell proliferation and EMT. ${ }^{49-51}$ Approximately $40 \%$ of malignant tumors are related to alterations of the PI3K/PTEN/AKT/mTOR cascade, which underscores the potential of the PI3K/PTEN/AKT/mTOR pathway as a target for clinical treatment. LncRNAs mainly affect the expression of related proteins to modulate signaling pathways, such as AB073614, DUXAP10, RP11-708H21.4, and lncRNA-422. ${ }^{51-54}$ In addition, PlncRNA- 1 regulates the phosphorylation of PI3K and AKT. ${ }^{50}$

\section{LncRNAs affect CRC cells through MAPK cascade}

Studies have demonstrated that most human cancers are related to a biomolecular event, the activation of Ras/MAPK signaling. ${ }^{55}$ Activation of the Ras/MAPK pathway promotes cell proliferation, migration, and differentiation. ${ }^{56,57}$ Conversely, inhibition of this pathway in CRC cells suppresses tumor development. The lncRNA CRNDE is important in the regulation of Ras/MAPK pathways. In addition, hnRNPUL2 can increase the stability of CRNDE to act as a vital mediator, thereby activating the Ras/MAPK cascade. ${ }^{58}$ Wang, et al. ${ }^{59}$ showed that the activity of the MAPK/Erk signaling pathway is regulated by the lncRNA NNT-AS1 and that activation of the MAPK/ Erk signaling pathway can induce EMT in CRC cells, increasing CRC cell proliferation, invasion, and migration.

\section{LncRNAs affect CRC cells through the p53 pathway}

P53 is a well-known tumor suppressor that is associated with CRC. Overexpression of p53 promotes cell cycle arrest, apoptosis, and tumor suppression. ${ }^{60,61}$ LncRNAs are regulators and mediators of the p53 cascade, and the effect of many lncRNAs is mediated by regulating the expression of p53. For example, the lncRNAs PURPL, ROR, SNHG1, and ZFAS1 promote tumorigenicity in CRC by suppressing basal p53 levels. ${ }^{62-65}$ Furthermore, HNF1A-AS1 can repress the miR-34a/SIRT1/p53 feedback loop to down-regulate p53 and promote the metastasis of colon cancer. ${ }^{66}$ 


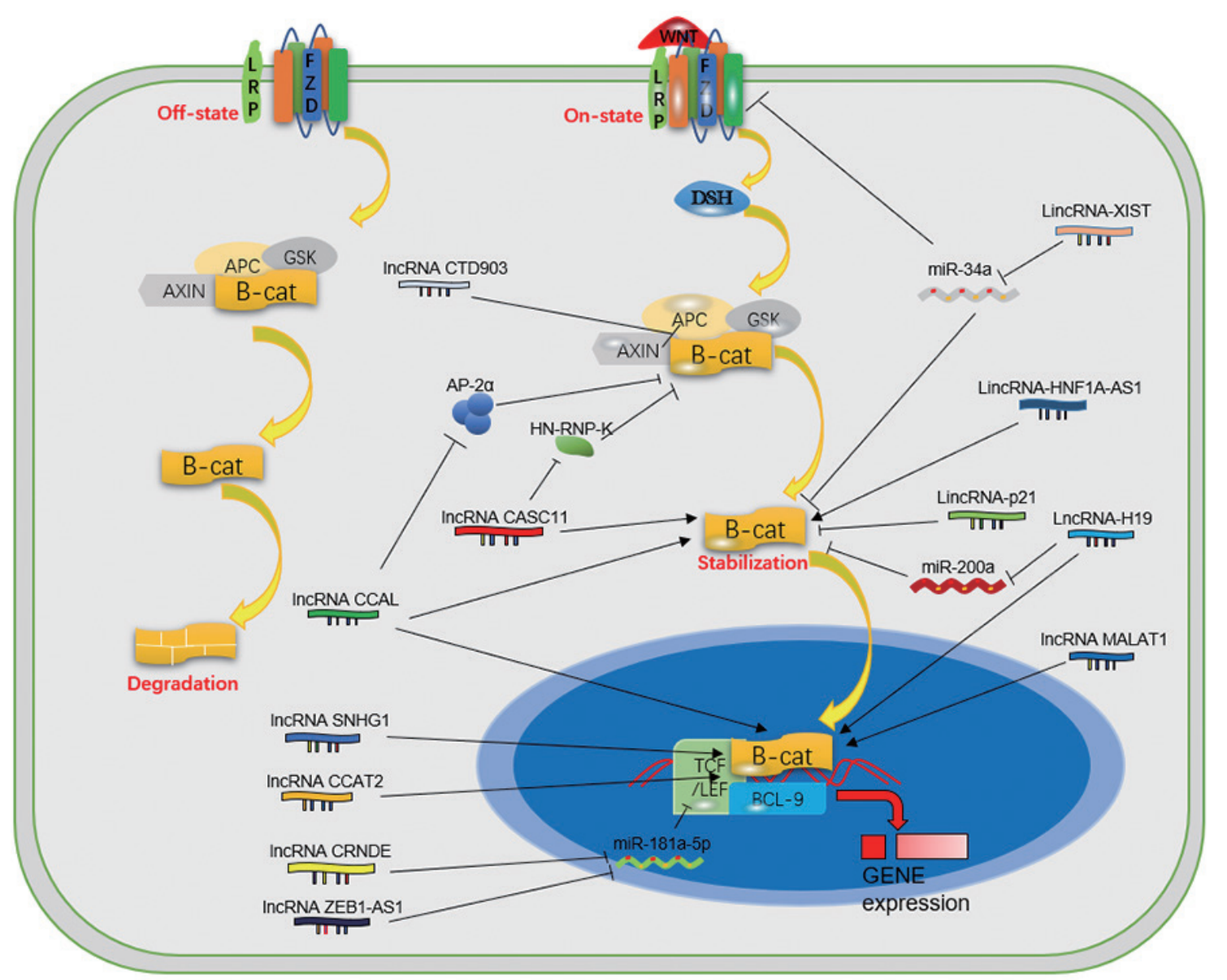

Fig. 1. The diverse regulatory mechanisms of IncRNAs on the Wnt signaling pathway. CCAL can activate Wnt/ $\beta$-catenin signaling pathway by down-regulating activator protein $2 \alpha$ (AP-2 $\alpha$ ), which can attenuate $\beta$-catenin/TCF-4 interactions and increase $\beta$-catenin. CASC11 can interact with hnRNP-K to induce the degradation of $\beta$-catenin and activate the Wnt/ $\beta$-catenin signaling pathway. MALAT1 can increase the nuclear localization of $\beta$-catenin and activate the pathway. SNHG1 can increase TCF-4 and $\beta$-catenin expression, leading to the nuclear accumulation of $\beta$-catenin and activation of the $\beta$-catenin pathway. CRNDE and ZEB1-AS1 can activate the Wnt/ $\beta$-catenin signaling pathway through sponging miR-181a-5p. LincRNA-p21 and CTD903 can reduce the levels of $\beta$-catenin in CRC cells. $\mathrm{H} 19$ competitively binds to miR-200a and indirectly increases $\beta$-catenin expression in CRC. CCAT2 overexpression inhibits $\beta$-catenin expression in CRC cells. HNF1A-AS1 can up-regulate the expression of $\beta$-catenin, cyclinD1, and c-Myc. LncRNA XIST binds to miR-34a, which can rescue the dysregulation of WNT1 and $\beta$-catenin. IncRNA, long noncoding RNA; CRC, colorectal cancer.

\section{LncRNAs affect CRC cells by modulating the Notch signaling pathway}

The Notch signaling pathway is involved in the tumorigenesis of various cancers including CRC. ${ }^{67,68}$ The cascade is observed in the processes of CRC cell proliferation, invasion, and metastasis. In addition, Notch signaling regulates EMT. ${ }^{69}$ The $\mathrm{ln}$ cRNA FAM83HAS1 is overexpressed in CRC cell lines and tissues concomitant with the up-regulation of two Notch signaling molecules, Notch1 and Hes1, thereby regulating the progression of CRC..$^{70}$ FOXD2-AS1 also regulates Notch signaling, acting as a tumor promoter in CRC. ${ }^{69}$

\section{LncRNAs affect CRC through the NF- $\kappa$ B signaling pathway} The transcription factor NF- $\mathrm{kB}$ was identified as a nuclear factor in 1986 and later shown to bind to enhancer elements to exert tumorigenic effects. ${ }^{71,72}$ Under physiological conditions, $\mathrm{NF}-\mathrm{\kappa B}$ is inhibited by many proteins. When these proteins are phosphorylated, NF- $\mathrm{kB}$ is activated and translocated to the nucleus to promote the initiation and progression of CRC. ${ }^{73}$ Most lncRNAs regulate this cascade by directly or indirectly modulating NF- $\kappa$ B. For example, lnc-GNAT1-1 exerts suppressive functions in CRC through the RKIP-NF-кB-Snail circuit, and lnc-GNAT1-1 knockdown downregulates PKIP and increases NF- $\mathrm{\kappa B}$ expression. ${ }^{74}$ The lncRNA GAS5 can decrease the phosphorylation of NF- $\mathrm{\kappa B}$ to activate NF- $\mathrm{KB}$ signaling. ${ }^{75} \mathrm{In}$ addition, the NF- $\mathrm{KB}$ cascade is associated with 5 -fluoropyrimidine resistance caused by IncRNA HOTAIR in CRC. ${ }^{76}$

\section{LncRNAs affect CRC cells by several other mechanisms}

\section{Caspase cleavage cascade}

Apoptosis signaling can induce caspase expression, which may affect the progression of CRC. The overexpression of lncRNA loc554202 can promote Gl arrest and cause apoptosis to inhibit CRC cell proliferation, mainly via caspase cleavage cascade. $^{77}$ 


\section{Chemokine signaling}

Chemokines play an important role in promoting CRC invasion and metastasis. ${ }^{78}$ The lncRNA MALAT1 promotes the progression of colon cancer through tumor-associated dendritic cells (TADCs), and using neutralizing antibodies or siRNA transfection to block chemokine ligand 5 could diminish the promotion of colon cancer induced by TADCs. ${ }^{79}$

\section{Interleukin pathway}

Interleukins (ILs) are related to the development of cancer. ${ }^{80,81}$ The lncRNA DILC has been found to be negatively associated with the proliferation and metastasis of CRC via the IL-6/ STAT3 cascade. ${ }^{82}$ IL-10 is associated with CRC cell proliferation and colony formation in relation to lncRNA GAS5. ${ }^{75}$

\section{PERSPECTIVES}

LncRNAs account for more than $80 \%$ of ncRNAs and generally have a lower transcriptional level than that of chromosome modification, transcriptional regulation, post-transcriptional processing, epigenetic, and nuclear import. ${ }^{11}$ Recent studies focusing on signaling pathways involved in cellular transformation have identified many cascades as potential treatment targets. ${ }^{47}$ Several lncRNAs associated with the regulation of signaling pathways have been identified, and lncRNAs have become ideal biomarkers for early diagnosis, therapeutic evaluation, and prognostic prediction in cancer. ${ }^{83}$ An extensive body of research has demonstrated that a number of cellular signaling pathways initiate and induce the progression of CRC, including the Wnt/ $\beta$-catenin pathway, the JAK/STAT pathway, the p53 pathway, the MAPK pathway, the PI3K/ PTEN/AKT/mTOR pathway, the Notch signaling pathway, and the NF- $\kappa \mathrm{B}$ signaling pathway. ${ }^{84}$ We investigated the effects of lncRNAs on signaling pathways and found that many lncRNAs control CRC properties by targeting different components thereof. Some components of signaling pathways have become attractive therapeutic targets because of their important functions in cancer. For instance, resveratrol can inhibit invasion and metastasis of CRC through MALAT1 because MALAT1 upregulates $\beta$-catenin and triggers its transfer to the nucleus. ${ }^{32}$ However, there are still no candidates for clinical application because of serious side effects, as proper signaling pathway activity is essential to sustaining normal cell survival. How to precisely regulate signaling pathways is challenging. Targeting these regulatory lncRNAs may be an alternative approach with which to achieve precise modulation of signaling pathways.

\section{CONCLUSION}

We summarized multiple functions and signaling pathways re- lated to lncRNAs in CRC cells and highlighted their potential clinical applications as novel diagnostic and prognostic biomarkers and therapeutic targets. Our review provides new insights with which to better understand CRC and points toward the potential for IncRNA-based therapeutic strategies for CRC.

\section{ACKNOWLEDGEMENTS}

This study was supported by the Research Fund of Development and Reform Commission of Jilin Province (2016C051-2).

\section{AUTHOR CONTRIBUTIONS}

Conceptualization: Jiaming Zhu. Data curation: Chao Chen. Formal analysis: Yuanda Liu. Funding acquisition: Jiaming Zhu. Investigation: Xiaohuan Tang. Methodology: Jingjing Liu. Project administration: Jiaming Zhu. Resources: Xiaofang Qiao. Software: Chao Chen. Supervision: Jingjing Liu. Validation: Xiaofang Qiao. Visualization: Xiaohuan Tang. Writing_original draft: Xiaohuan Tang. Writingreview \& editing: Jingjing Liu.

\section{ORCID iDs}

$\begin{array}{ll}\text { Xiaohuan Tang } & \text { https://orcid.org/0000-0001-9526-6984 } \\ \text { Xiaofang Qiao } & \text { https://orcid.org/0000-0001-6134-5270 } \\ \text { Chao Chen } & \text { https://orcid.org/0000-0001-9092-2460 } \\ \text { Yuanda Liu } & \text { https://orcid.org/0000-0002-5095-8466 } \\ \text { Jiaming Zhu } & \text { https://orcid.org/0000-0002-8637-5406 } \\ \text { Jingjing Liu } & \text { https://orcid.org/0000-0003-3112-0147 }\end{array}$

\section{REFERENCES}

1. Bray F, Ferlay J, Soerjomataram I, Siegel RL, Torre LA, Jemal A. Global cancer statistics 2018: GLOBOCAN estimates of incidence and mortality worldwide for 36 cancers in 185 countries. CA Cancer J Clin 2018;68:394-424.

2. Chen W, Zheng R, Zhang S, Zhao P, Zeng H, Zou X. Report of cancer incidence and mortality in China, 2010. Ann Transl Med 2014; 2:61.

3. Elias D, Faron M, Iuga BS, Honoré C, Dumont F, Bourgain JL, et al. Prognostic similarities and differences in optimally resected liver metastases and peritoneal metastases from colorectal cancers. Ann Surg 2015;261:157-63.

4. D'Andrea V, Panarese A, Tonda M, Biffoni M, Monti M. Cancer stem cells as functional biomarkers. Cancer Biomark 2017;20: 231-4.

5. Abetov D, Mustapova Z, Saliev T, Bulanin D. Biomarkers and signaling pathways of colorectal cancer stem cells. Tumour Biol 2015; 36:1339-53.

6. Samuels Y, Velculescu VE. Oncogenic mutations of PIK3CA in human cancers. Cell Cycle 2004;3:1221-4.

7. Kim M, Suh YA, Oh JH, Lee BR, Kim J, Jang SJ. KIF3A binds to $\beta$-arrestin for suppressing Wnt/ $\beta$-catenin signalling independently of primary cilia in lung cancer. Sci Rep 2016;6:32770.

8. Lee W, Yun JM. Suppression of $\beta$-catenin signaling pathway in human prostate cancer PC3 cells by delphinidin. J Cancer Prev 2016;21:110-4.

9. Sebio A, Kahn M, Lenz HJ. The potential of targeting Wnt $/ \beta$-catenin in colon cancer. Expert Opin Ther Targets 2014;18:611-5. 
10. Bhan A, Soleimani M, Mandal SS. Long noncoding RNA and cancer: a new paradigm. Cancer Res 2017;77:3965-81.

11. Cao J. The functional role of long non-coding RNAs and epigenetics. Biol Proced Online 2014;16:11.

12. Rinn JL, Chang HY. Genome regulation by long noncoding RNAs. Annu Rev Biochem 2012;81:145-66.

13. Nissan A, Stojadinovic A, Mitrani-Rosenbaum S, Halle D, Grinbaum R, Roistacher M, et al. Colon cancer associated transcript-1: a novel RNA expressed in malignant and pre-malignant human tissues. Int J Cancer 2012;130:1598-606.

14. Chen X, Liu B, Yang R, Guo Y, Li F, Wang L, et al. Integrated analysis of long non-coding RNAs in human colorectal cancer. Oncotarget 2016; 7:23897-908.

15. Sun J, Ding C, Yang Z, Liu T, Zhang X, Zhao C, et al. The long noncoding RNA TUG1 indicates a poor prognosis for colorectal cancer and promotes metastasis by affecting epithelial-mesenchymal transition. J Transl Med 2016;14:42.

16. Taniue K, Kurimoto A, Sugimasa H, Nasu E, Takeda Y, Iwasaki K, et al. Long noncoding RNA UPAT promotes colon tumorigenesis by inhibiting degradation of UHRF1. Proc Natl Acad Sci U S A 2016; 113:1273-8

17. Xue J, Liao L, Yin F, Kuang H, Zhou X, Wang Y. LncRNA AB073614 induces epithelial-mesenchymal transition of colorectal cancer cells via regulating the JAK/STAT3 pathway. Cancer Biomark 2018; 21:849-58.

18. Ma Y, Yang Y, Wang F, Moyer MP, Wei Q, Zhang P, et al. Long noncoding RNA CCAL regulates colorectal cancer progression by activating $\mathrm{Wnt} / \beta$-catenin signalling pathway via suppression of activator protein $2 \alpha$. Gut 2016;65:1494-504.

19. Kim SH, Park KH, Shin SJ, Lee KY, Kim TI, Kim NK, et al. CpG island methylator phenotype and methylation of Wnt pathway genes together predict survival in patients with colorectal cancer. Yonsei Med J 2018;59:588-94.

20. MacDonald BT, Tamai K, He X. Wnt/beta-catenin signaling: components, mechanisms, and diseases. Dev Cell 2009;17:9-26.

21. Faber C, Kirchner T, Hlubek F. The impact of microRNAs on colorectal cancer. Virchows Arch 2009;454:359-67.

22. Clevers H, Nusse R. Wnt/ $\beta$-catenin signaling and disease. Cell 2012;149:1192-205.

23. Yuan Z, Yu X, Ni B, Chen D, Yang Z, Huang J, et al. Overexpression of long non-coding RNA-CTD903 inhibits colorectal cancer invasion and migration by repressing $\mathrm{Wnt} / \beta$-catenin signaling and predicts favorable prognosis. Int J Oncol 2016;48:2675-85.

24. Thiery JP, Acloque H, Huang RY, Nieto MA. Epithelial-mesenchymal transitions in development and disease. Cell 2009;139:871-90.

25. Zhou J, Li X, Wu M, Lin C, Guo Y, Tian B. Knockdown of long noncoding RNA GHET1 inhibits cell proliferation and invasion of colorectal cancer. Oncol Res 2016;23:303-9.

26. Chen DL, Chen LZ, Lu YX, Zhang DS, Zeng ZL, Pan ZZ, et al. Long noncoding RNA XIST expedites metastasis and modulates epithelial-mesenchymal transition in colorectal cancer. Cell Death Dis 2017;8:e3011.

27. Li Z, Tang Y, Xing W, Dong W, Wang Z. LncRNA, CRNDE promotes osteosarcoma cell proliferation, invasion and migration by regulating Notch1 signaling and epithelial-mesenchymal transition. Exp Mol Pathol 2018;104:19-25.

28. Lin J, Shi Z, Yu Z, He Z. LncRNA HIF1A-AS2 positively affects the progression and EMT formation of colorectal cancer through regulating miR-129-5p and DNMT3A. Biomed Pharmacother 2018; 98:433-9.

29. Wu ZH, Wang XL, Tang HM, Jiang T, Chen J, Lu S, et al. Long noncoding RNA HOTAIR is a powerful predictor of metastasis and poor prognosis and is associated with epithelial-mesenchymal transition in colon cancer. Oncol Rep 2014;32:395-402.

30. Zhang Z, Zhou C, Chang Y, Zhang Z, Hu Y, Zhang F, et al. Long non-coding RNA CASC11 interacts with hnRNP-K and activates the $\mathrm{WNT} / \beta$-catenin pathway to promote growth and metastasis in colorectal cancer. Cancer Lett 2016;376:62-73.

31. Ling H, Spizzo R, Atlasi Y, Nicoloso M, Shimizu M, Redis RS, et al. CCAT2, a novel noncoding RNA mapping to 8q24, underlies metastatic progression and chromosomal instability in colon cancer. Genome Res 2013;23:1446-61.

32. Ji Q, Liu X, Fu X, Zhang L, Sui H, Zhou L, et al. Resveratrol inhibits invasion and metastasis of colorectal cancer cells via MALAT1 mediated Wnt/ $\beta$-catenin signal pathway. PLoS One 2013;8: e78700.

33. Zhu Y, Li B, Liu Z, Jiang L, Wang G, Lv M, et al. Up-regulation of lncRNA SNHG1 indicates poor prognosis and promotes cell proliferation and metastasis of colorectal cancer by activation of the Wnt/ $\beta$-catenin signaling pathway. Oncotarget 2017;8:111715-27.

34. Han P, Li JW, Zhang BM, Lv JC, Li YM, Gu XY, et al. The lncRNA CRNDE promotes colorectal cancer cell proliferation and chemoresistance via miR-181a-5p-mediated regulation of Wnt/ $\beta$-catenin signaling. Mol Cancer 2017;16:9.

35. Lv SY, Shan TD, Pan XT, Tian ZB, Liu XS, Liu FG, et al. The lncRNA ZEB1-AS1 sponges miR-181a-5p to promote colorectal cancer cell proliferation by regulating Wnt/ $\beta$-catenin signaling. Cell Cycle 2018;17:1245-54.

36. Yang W, Ning N, Jin X. The lncRNA H19 promotes cell proliferation by competitively binding to miR-200a and derepressing $\beta$-catenin expression in colorectal cancer. Biomed Res Int 2017; 2017:2767484.

37. Wang J, Lei ZJ, Guo Y, Wang T, Qin ZY, Xiao HL, et al. miRNA-regulated delivery of lincRNA-p21 suppresses $\beta$-catenin signaling and tumorigenicity of colorectal cancer stem cells. Oncotarget 2015;6:37852-70.

38. Sun N, Zhang G, Liu Y. Long non-coding RNA XIST sponges miR34 a to promotes colon cancer progression via Wnt/ $\beta$-catenin signaling pathway. Gene 2018;665:141-8.

39. Zhang X, Xiong Y, Tang F, Bian Y, Chen Y, Zhang F. Long noncoding RNA HNF1A-AS1 indicates a poor prognosis of colorectal cancer and promotes carcinogenesis via activation of the Wnt/ $\beta$-catenin signaling pathway. Biomed Pharmacother 2017;96:877-83.

40. Xie F, Xiang X, Huang Q, Ran P, Yuan Y, Li Q, et al. Reciprocal control of lncRNA-BCAT1 and $\beta$-catenin pathway reveals lncRNABCAT1 long non-coding RNA acts as a tumor suppressor in colorectal cancer. Oncotarget 2017;8:23628-37.

41. Akira S. Functional roles of STAT family proteins: lessons from knockout mice. Stem Cells 1999;17:138-46.

42. Costa-Pereira AP, Bonito NA, Seckl MJ. Dysregulation of janus kinases and signal transducers and activators of transcription in cancer. Am J Cancer Res 2011;1:806-16.

43. Teng Y, Ross JL, Cowell JK. The involvement of JAK-STAT3 in cell motility, invasion, and metastasis. JAKSTAT 2014;3:e28086.

44. Shi D, Liang L, Zheng H, Cai G, Li X, Xu Y, et al. Silencing of long non-coding RNA SBDSP1 suppresses tumor growth and invasion in colorectal cancer. Biomed Pharmacother 2017;85:355-61.

45. Zhou W, Wang L, Miao Y, Xing R. Novel long noncoding RNA GACAT3 promotes colorectal cancer cell proliferation, invasion, and migration through miR-149. Onco Targets Ther 2018;11:1543-52.

46. Huang G, Wu X, Li S, Xu X, Zhu H, Chen X. The long noncoding RNA CASC2 functions as a competing endogenous RNA by sponging miR-18a in colorectal cancer. Sci Rep 2016;6:26524.

47. Fresno Vara JA, Casado E, de Castro J, Cejas P, Belda-Iniesta C, González-Barón M. PI3K/Akt signalling pathway and cancer. Cancer Treat Rev 2004;30:193-204. 
48. Milella M, Falcone I, Conciatori F, Cesta Incani U, Del Curatolo A, Inzerilli N, et al. PTEN: multiple functions in human malignant tumors. Front Oncol 2015;5:24.

49. Rodgers SJ, Ferguson DT, Mitchell CA, Ooms LM. Regulation of PI3K effector signalling in cancer by the phosphoinositide phosphatases. Biosci Rep 2017;37:BSR20160432.

50. Song W, Mei JZ, Zhang M. Long noncoding RNA PlncRNA-1 promotes colorectal cancer cell progression by regulating the PI3K/ Akt signaling pathway. Oncol Res 2018;26:261-8.

51. Wang Y, Kuang H, Xue J, Liao L, Yin F, Zhou X. LncRNA AB073614 regulates proliferation and metastasis of colorectal cancer cells via the PI3K/AKT signaling pathway. Biomed Pharmacother 2017; 93:1230-7.

52. Lian Y, Xu Y, Xiao C, Xia R, Gong H, Yang P, et al. The pseudogene derived from long non-coding RNA DUXAP10 promotes colorectal cancer cell growth through epigenetically silencing of p21 and PTEN. Sci Rep 2017;7:7312.

53. Sun L, Jiang C, Xu C, Xue H, Zhou H, Gu L, et al. Down-regulation of long non-coding RNA RP11-708H21.4 is associated with poor prognosis for colorectal cancer and promotes tumorigenesis through regulating AKT/mTOR pathway. Oncotarget 2017;8:2792942.

54. Shao Q, Xu J, Deng R, Wei W, Zhou B, Yue C, et al. Long non-coding RNA-422 acts as a tumor suppressor in colorectal cancer. Biochem Biophys Res Commun 2018;495:539-45.

55. Donninger H, Schmidt ML, Mezzanotte J, Barnoud T, Clark GJ. Ras signaling through RASSF proteins. Semin Cell Dev Biol 2016; 58:86-95.

56. Cidre-Aranaz F, Grünewald TG, Surdez D, García-García L, Carlos Lázaro J, Kirchner T, et al. EWS-FLI1-mediated suppression of the RAS-antagonist Sprouty 1 (SPRY1) confers aggressiveness to Ewing sarcoma. Oncogene 2017;36:766-76.

57. Huang X, Schwind S, Santhanam R, Eisfeld AK, Chiang CL, Lankenau M, et al. Targeting the RAS/MAPK pathway with miR-181a in acute myeloid leukemia. Oncotarget 2016;7:59273-86.

58. Jiang H, Wang Y, Ai M, Wang H, Duan Z, Wang H, et al. Long noncoding RNA CRNDE stabilized by hnRNPUL2 accelerates cell proliferation and migration in colorectal carcinoma via activating Ras/MAPK signaling pathways. Cell Death Dis 2017;8:e2862.

59. Wang Q, Yang L, Hu X, Jiang Y, Hu Y, Liu Z,et al. Upregulated NNT-AS1, a long noncoding RNA, contributes to proliferation and migration of colorectal cancer cells in vitro and in vivo. Oncotarget 2017;8:3441-53.

60. Levine AJ. p53, the cellular gatekeeper for growth and division. Cell 1997;88:323-31.

61. Budanov AV. The role of tumor suppressor p53 in the antioxidant defense and metabolism. Subcell Biochem 2014;85:337-58.

62. Li XL, Subramanian M, Jones MF, Chaudhary R, Singh DK, Zong $\mathrm{X}$, et al. Long noncoding RNA PURPL suppresses basal p53 levels and promotes tumorigenicity in colorectal cancer. Cell Rep 2017; 20:2408-23.

63. Li H, Jiang X, Niu X. Long non-coding RNA reprogramming (ROR) promotes cell proliferation in colorectal cancer via affecting P53. Med Sci Monit 2017;23:919-28.

64. Zhao Y, Qin ZS, Feng Y, Tang XJ, Zhang T, Yang L. Long non-coding RNA (lncRNA) small nucleolar RNA host gene 1 (SNHG1) promote cell proliferation in colorectal cancer by affecting P53. Eur Rev Med Pharmacol Sci 2018;22:976-84.

65. Thorenoor N, Faltejskova-Vychytilova P, Hombach S, Mlcochova J, Kretz M, Svoboda M, et al. Long non-coding RNA ZFAS1 interacts with CDK1 and is involved in p53-dependent cell cycle control and apoptosis in colorectal cancer. Oncotarget 2016;7:622-37.
66. Fang C, Qiu S, Sun F, Li W, Wang Z, Yue B, et al. Long non-coding RNA HNF1A-AS1 mediated repression of miR-34a/SIRT1/p53 feedback loop promotes the metastatic progression of colon cancer by functioning as a competing endogenous RNA. Cancer Lett 2017;410:50-62.

67. Badenes M, Trindade A, Pissarra H, Lopes-da-Costa L, Duarte A. Erratum to: delta-like 4/notch signaling promotes $\mathrm{Apc}^{\mathrm{Min} /+}$ tumor initiation through angiogenic and non-angiogenic related mechanisms. BMC Cancer 2017;17:205.

68. Fujiki K, Inamura H, Miyayama T, Matsuoka M. Involvement of Notch1 signaling in malignant progression of A549 cells subjected to prolonged cadmium exposure. J Biol Chem 2017;292:7942-53.

69. Yang X, Duan B, Zhou X. Long non-coding RNA FOXD2-AS1 functions as a tumor promoter in colorectal cancer by regulating EMT and Notch signaling pathway. Eur Rev Med Pharmacol Sci 2017;21:3586-91.

70. Lu S, Dong W, Zhao P, Liu Z. IncRNA FAM83H-AS1 is associated with the prognosis of colorectal carcinoma and promotes cell proliferation by targeting the Notch signaling pathway. Oncol Lett 2018;15:1861-8.

71. Hoesel B, Schmid JA. The complexity of NF- $\kappa B$ signaling in inflammation and cancer. Mol Cancer 2013;12:86.

72. Sen R, Baltimore D. Multiple nuclear factors interact with the immunoglobulin enhancer sequences. Cell 1986;46:705-16.

73. Vaiopoulos AG, Athanasoula KCh, Papavassiliou AG. NF- $\kappa$ B in colorectal cancer. J Mol Med (Berl) 2013;91:1029-37.

74. Ye C, Shen Z, Wang B, Li Y, Li T, Yang Y, et al. A novel long noncoding RNA lnc-GNAT1-1 is low expressed in colorectal cancer and acts as a tumor suppressor through regulating RKIP-NF- $\kappa B-S n a i l$ circuit. J Exp Clin Cancer Res 2016;35:187.

75. Li Y, Li Y, Huang S, He K, Zhao M, Lin H, et al. Long non-coding RNA growth arrest specific transcript 5 acts as a tumour suppressor in colorectal cancer by inhibiting interleukin-10 and vascular endothelial growth factor expression. Oncotarget 2017;8:13690-702.

76. Li P, Zhang X, Wang L, Du L, Yang Y, Liu T, et al. IncRNA HOTAIR contributes to $5 \mathrm{FU}$ resistance through suppressing miR-218 and activating NF- $\mathrm{KB} / \mathrm{TS}$ signaling in colorectal cancer. Mol Ther Nucleic Acids 2017;8:356-69.

77. Ding J, Lu B, Wang J, Wang J, Shi Y, Lian Y, et al. Long non-coding RNA Loc554202 induces apoptosis in colorectal cancer cells via the caspase cleavage cascades. J Exp Clin Cancer Res 2015;34:100.

78. Itatani Y, Kawada K, Inamoto S, Yamamoto T, Ogawa R, Taketo $\mathrm{MM}$, et al. The role of chemokines in promoting colorectal cancer invasion/metastasis. Int J Mol Sci 2016;17:643.

79. Kan JY, Wu DC, Yu FJ, Wu CY, Ho YW, Chiu YJ, et al. Chemokine (C-C Motif) ligand 5 is involved in tumor-associated dendritic cell-mediated colon cancer progression through non-coding RNA MALAT-1. J Cell Physiol 2015;230:1883-94.

80. Chen YY, Li CF, Yeh CH, Chang MS, Hsing CH. Interleukin-19 in breast cancer. Clin Dev Immunol 2013;2013:294320.

81. Zhou B, Shu B, Yang J, Liu J, Xi T, Xing Y. C-reactive protein, interleukin- 6 and the risk of colorectal cancer: a meta-analysis. Cancer Causes Control 2014;25:1397-405.

82. Gu LQ, Xing XL, Cai H, Si AF, Hu XR, Ma QY, et al. Long non-coding RNA DILC suppresses cell proliferation and metastasis in colorectal cancer. Gene 2018;666:18-26.

83. Evans JR, Feng FY, Chinnaiyan AM. The bright side of dark matter: IncRNAs in cancer. J Clin Invest 2016;126:2775-82.

84. Walther A, Johnstone E, Swanton C, Midgley R, Tomlinson I, Kerr D. Genetic prognostic and predictive markers in colorectal cancer. Nat Rev Cancer 2009;9:489-99. 